\title{
How to Manage Atrial Fibrillation in the Emergency Department: a Critical Appraisal
}

Rafael Thiesen Magliari, ${ }^{1,2,3}$, José Nunes de Alencar Neto ${ }^{3,4, *}$

ORCID IDs

Magliari RT (iD https://orcid.org/0000-0002-3839-6253

Alencar Neto JN (D) https://orcid.org/0000-0002-3835-6067

\begin{abstract}
Atrial fibrillation is the most common cardiac arrhythmia in emergency departments. There is growing evidence that certain patients with acute atrial fibrillation can be safely managed in the emergency room without the need for hospitalization, minimizing costs and reducing unnecessary exposures. This review addresses the emergency management of atrial fibrillation based on the latest updates on the subject with a focus on the assessment and prevention of thromboembolic phenomena, control of frequency vs rhythm control and strategies for cardioversion and restoration of sinus rhythm or for heart rate control.
\end{abstract}

KEYWORDS: Atrial fibrillation; Cardioversion; Electrical cardioversion; Emergency department; Cardiac arrhythmias; Anticoagulants.

1. Hospital Santa Paula - São Paulo (SP), Brazil.

2. Centro de Arritmias e Eletrofisiologia Cardíaca - São Paulo (SP), Brazil.

3.Sociedade Brasileira de Arritmias Cardíacas - São Paulo (SP), Brazil.

4. Instituto Dante Pazzanese de Cardiologia - São Paulo (SP), Brazil.

*Correspondence author: josenunesalencar@gmail.com

Received: 13 May 2020 | Accepted: 23 May 2020 


\section{INTRODUCTION}

Atrial fibrillation (AF) is the most common cardiac arrhythmia in the world, which is why patients with AF are often seen in emergency services ${ }^{1}$. The number of hospitalizations for AF has been increasing in recent years with rising health costs, while many patients can be safely treated in the emergency rooms to later be discharged home, without the need for hospitalization ${ }^{2,3}$. In the context of the emergency room, the main objectives of the treatment of this arrhythmia should be: (a) the prevention of thromboembolic events; (b) avoidance of hemodynamic instabilities, (c) control of the patient's symptoms, (d) identification and treatment of the precipitating cause. For stable patients with recent onset AF, a strategy of frequency control or rhythm control can be adopted based on several factors, including the duration of $\mathrm{AF}$ and the severity of symptoms. If a rhythm control strategy is chosen, control can be achieved using electrical or pharmacological cardioversion.

\section{EPIDEMIOLOGY}

The incidence and prevalence of AF has been increasing over time and is expected to grow even more in the future. This trend seems to be explained by the increase in age in the general population, an increase in the prevalence of obesity, improved survival after a first cardiovascular event and new technologies for the detection of AF and other arrhythmias ${ }^{4}$. There are several risk factors that contribute to the appearance and perpetuation of atrial AF. Nevertheless, age is the main risk factor ${ }^{5}$. Among the modifiable risk factors, the most prominent are obesity and systemic arterial hypertension. In the case of obesity, an important study has shown that weight loss is directly related to the evolution to paroxysmal forms ${ }^{6}$.

\section{CLASSIFICATION}

The classification of AF starts with a distinction of a first detectable episode, associated with a symptom or self-limited. According to guidelines from the American College of Cardiology (ACC) / American Heart Association (AHA) / Heart Rhythm Society (HRS) ${ }^{7,8}$, an AF classification is recommended in the following standards (Fig. 1):

- Paroxysmal AF: detection of AF that reverts spontaneously in less than 7 days (most episodes last less than $24 \mathrm{~h}$ );

- Persistent AF: AF episodes that last more than 7 days and may require pharmacological or electrical intervention for reversion;

- Long-term persistent AF: AF that has persisted for more than 12 months;

- Permanent AF: when the patient and the doctor decided to abort restoration strategies after shared clinical decision-making.

It is noteworthy that the use of the terms "chronic AF" and "isolated AF" is discouraged by these same societies?

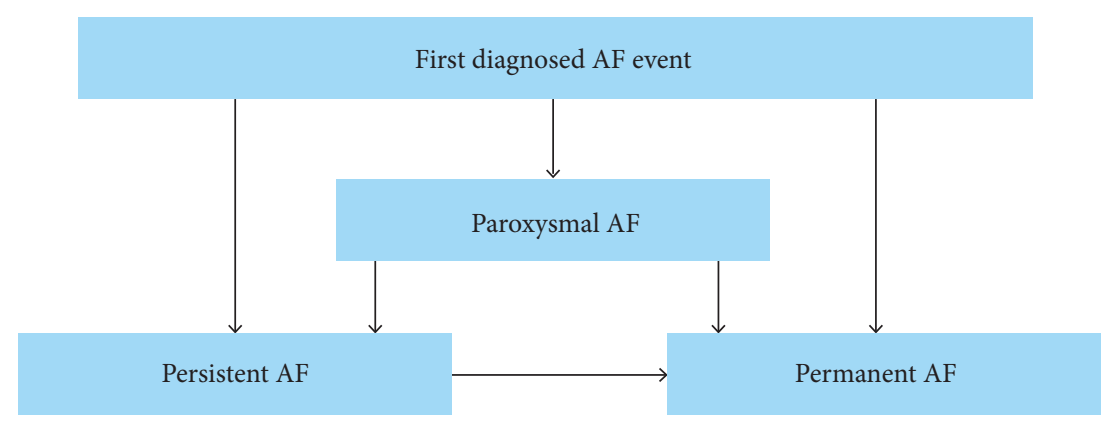

Figure 1. Classification of atrial fibrillation (AF), taking into account the presentation and duration of the episode. Paroxysmal (usually $<48 \mathrm{~h}$ ); persistent ( $>7$ days or cardioversion required) and permanent (without planning an approach to reverse the rhythm). 


\section{CLINICAL PRESENTATION}

The manifestations of the arrhythmia are very variable, affecting from asymptomatic people who are unaware of their clinical condition until the moment it is eventually discovered during a physical examination, and also patients who present symptoms such as: palpitations, weakness, reduced ability to exercise, fatigue, dizziness, dyspnea and chest pain. Such complaints are due to a high heart rate and to the loss of atrial contraction, with its respective hemodynamic contribution. Syncope due to arrhythmia is uncommon and, in these cases, high-ventricular response AF with accessory conduction or its association with total atrioventricular block should be suspected.

Atrial fibrillation also manifests itself through thromboembolic events. In patients at higher risk, a cardiac embolus, most commonly originating from the left atrial appendage, can cause an ischemic stroke and peripheral arterial embolism. The occurrence of these phenomena is related to the patient's clinical risk profile, whatever the type of AF (paroxysmal, persistent or permanent). Risk factors such as the presence of valve disease (mainly mitral valve disease), advanced age and a previous embolic event are correlated with a higher probability of a new cerebral ischemic event.

\section{EMERGENCY MANAGEMENT OF AF}

In the emergency room, the management of patients with $\mathrm{AF}$ aims to alleviate symptoms and prevent complications related to arrhythmia. For the correct decision regarding treatment, certain clinical information is essential: The length of the interval between the onset of symptoms and the arrival at the doctor, and the severity of symptoms. Treatment consists of a direct approach to the arrhythmia, by controlling heart rate or rhythm, and preventing thromboembolic events by anticoagulation.

There is no universally accepted approach to the treatment of AF in the emergency and there are many controversies regarding the two main strategies: heart rate control and rhythm management. Strategies to control rhythm or frequency can be effective in relieving symptoms, but none of them demonstrated superiority in reducing mortality when compared with each other ${ }^{10}$. Rhythm control strategies have shown better mortality outcomes, especially in patients over the age of 65 and diastolic ${ }^{11}$ and systolic ${ }^{12}$ heart failure.

Some comorbidities such as hyperthyroidism, acute coronary syndrome and exacerbated chronic obstructive pulmonary disease (COPD) can be the triggers for an $\mathrm{AF}$ crisis and the recognition and treatment of these conditions is essential for the adequate clinical outcome, since atrial arrhythmia can be a secondary manifestation to the main disease, which would require specific treatment that will not be the focus of this review.

\section{RHYTHM OR FREQUENCY CONTROL IN EMERGENCY SITUATIONS?}

Although international guidelines exist to guide the management of disease decompensation, the treatment of AF in emergency services is still heterogeneous ${ }^{13}$. The emergency physician must provide supplemental oxygen if necessary, establish venous access, continuous electrocardiographic monitoring, blood pressure and 12-lead electrocardiogram. The most important data in making therapeutic decisions are the duration of AF and its classification, heart rate, precipitating factors and signs and symptoms. Special attention should be paid to identifying signs of left ventricular hypertrophy, ventricular preexcitation, bundle branch block, previous myocardial infarction and other structural heart disease or lung disease. Acute AF in patients without structural heart disease will rarely develop hemodynamic instability, and the treatment of reversible and triggering causes of arrhythmia should be the primary objective ${ }^{13}$. The goals of AF treatment are: to relieve symptoms, improve functional capacity, improve quality of life, prevent tachycardia-induced cardiomyopathy and reduce hospitalization rates ${ }^{8}$.

In situations of atrial fibrillation with high ventricular response (HVR), the physician must estimate whether this patient is symptomatic because of or as a consequence of AF. Common clinical situations in a hospital environment, such as sepsis, digestive bleeding, among many others, can trigger decompensation of the arrhythmia. In these cases, treating heart rate and not the underlying cause can be ineffective and even harmful to the patient ${ }^{14}$. Careful evaluation by an experienced team member may be necessary to assess this dichotomy. 
In cases where HVR is considered to be the cause of the patient's instability and there is an imminent risk of death (progressive reduction in the level of consciousness, severe dyspnea with signs of respiratory distress, hypotensive circulatory shock), synchronized electrical cardioversion is recommended. To perform this therapy, sedation and analgesia are required, more commonly with short-term agents, such as the combination of propofol and fentany $1^{15}$, which have negative inotropic effects, potentially harmful to this particular patient. Different combinations, such as propofol + ketamine, dexmedetomidine + propofol, or remifentanil instead of fentanyl can be used according to the team's experience and availability ${ }^{16}$. A dose of 10,000 units of unfractionated heparin should be administered as a bolus intravenously, based on anecdotal evidence ${ }^{17}$. The atrial stunning that occurs after an electrical cardioversion can last from $24 \mathrm{~h}$ to 1 month, depending on the duration of atrial fibrillation ${ }^{18}$.

In patients who do not show clear signs of clinical or hemodynamic instability, the choice of strategy will depend on the choice of the doctor and the patient's preference: rhythm or frequency control. For this joint decision, the doctor must consider the embolic risk of the procedure, which is estimated by the time of occurrence of the arrhythmia: acute $(<48 \mathrm{~h})$ or subacute $(\geq 48 \mathrm{~h})$.

According to the recommendations, in stable cases of acute atrial fibrillation $(<48 \mathrm{~h})$, electrical $(89.7 \%$ success in $24 \mathrm{~h}$ ) or pharmacological $\left(69 \%\right.$ success in $24 \mathrm{~h}$ ) cardioversion can be performed ${ }^{19}$, following the same routine which was described for the unstable patient ${ }^{7,20}$, emphasizing that $70 \%$ of AF episodes revert spontaneously in less than $24 \mathrm{~h}^{21}$. This 48 -hour rule is arbitrary and lacks modern data. Since pharmacological and electrical cardioversion have associated risks, identifying patients in whom spontaneous conversion is likely to occur and avoiding active interventions can decrease cardioversion-related morbidity. A duration of symptoms of less than $24 \mathrm{~h}$ seems to be a good indicator of spontaneous reversion to sinus rhythm. Other clinical and echocardiographic variables such as age, sex, left atrium enlargement, left ventricle systolic dysfunction and use of drugs to control the ventricular rate were not spontaneous conversion predictors ${ }^{21}$.

A single-center retrospective study evidenced that cardioverted patients with acute $\mathrm{AF}$ ( $<48 \mathrm{~h}$ ) had a fivefold higher risk of subsequent embolic events when they did not receive prior anticoagulant therapy, challenging current practice ${ }^{22}$. In addition, the recently published RACE 7 ACWAS, which compared rhythm control strategies (cardioversion) with pharmacological heart rate control in patients with stable acute AF, there was a noninferiority for the heart rate control strategy in sinus rhythm maintenance in four weeks after admission ${ }^{23}$. The study has a slightly different methodology from that usually performed in emergencies and some statistical biases; therefore, the knowledge of its results is important, but also its reading and critical analysis. Heart rate control even in acute AF $(<48 \mathrm{~h}$ ), due to current evidence, and the primum non noncere philosophy, seems to be a strategy at least not inferior to classical strategies and is proposed in Fig. 2. Table 1 summarizes the drugs available for heart rate control strategy.

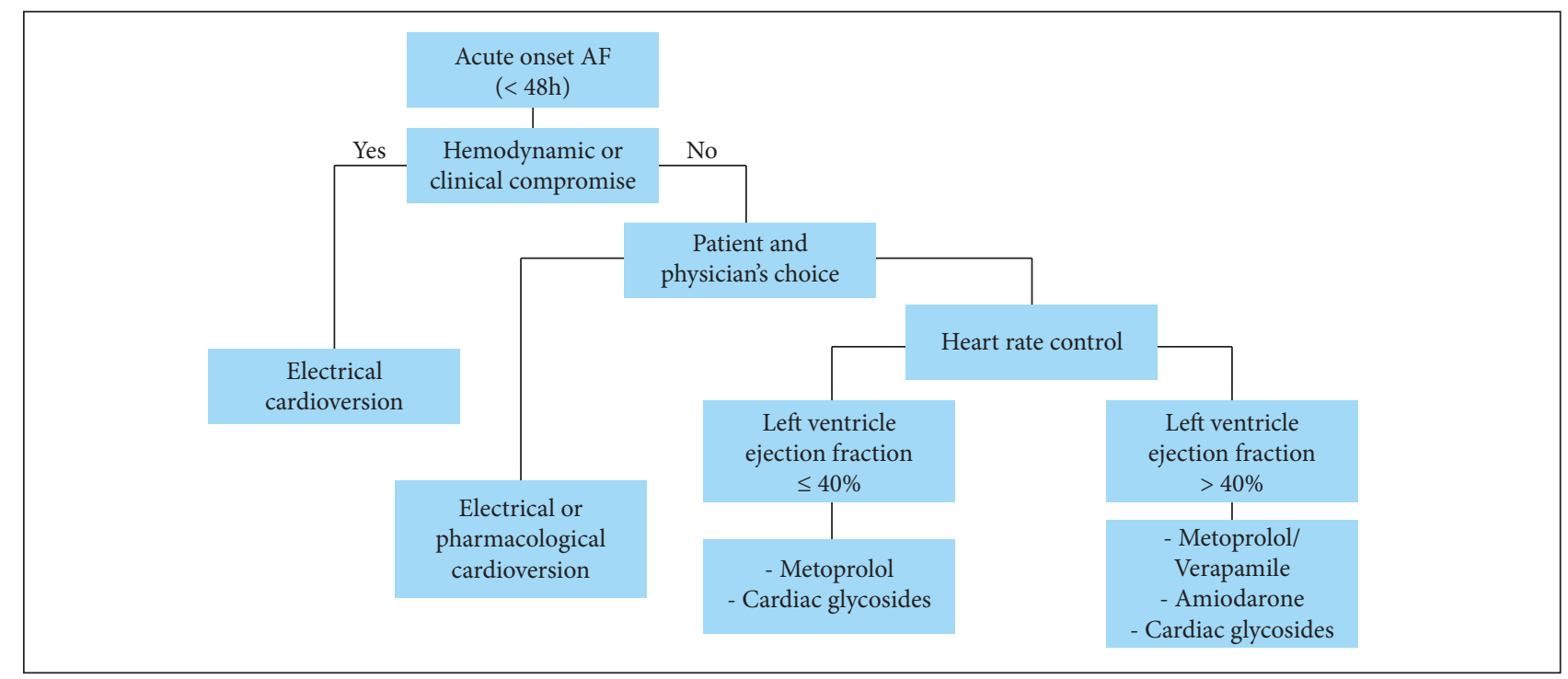

Figure 2. Urgent management of atrial fibrillation of acute onset $(<48 \mathrm{~h})$. 
Table 1. Drugs available in emergency rooms to control the frequency of atrial fibrillation in Brazil.

\begin{tabular}{|c|c|c|c|c|}
\hline Drug & $\begin{array}{c}\text { Route of } \\
\text { administration }\end{array}$ & Loading dose & $\begin{array}{l}\text { Maintenance } \\
\text { dose }\end{array}$ & Adverse events \\
\hline Metoprolol & Intravenous & $\begin{array}{l}5 \mathrm{mg} \text { bolus administered for } 2 \mathrm{~min} \\
\text { Repeated up to a dose of } 15 \mathrm{mg}\end{array}$ & $\begin{array}{l}100-200 \text { mg } \\
\text { orally daily }\end{array}$ & $\begin{array}{l}\text { Lethargy, headache, peripheral } \\
\text { edema, bronchospasm, bradycardia, } \\
\text { hypotension and atrioventricular block }\end{array}$ \\
\hline Amiodarone & Intravenous & $\begin{array}{l}300 \text { mg diluted in glucose solution } \\
\text { administered in } 30 \text { to } 60 \text { min }\end{array}$ & $\begin{array}{l}200 \text { mg orally } \\
\text { daily }\end{array}$ & $\begin{array}{l}\text { Hypotension, bradycardia, nausea, QT } \\
\text { interval prolongation, reversal to sinus } \\
\text { rhythm with risk of embolic events }\end{array}$ \\
\hline Deslanoside & Intravenous & $0.4 \mathrm{mg}$ in slow bolus & - & $\begin{array}{l}\text { Gastrointestinal discomfort, blurred } \\
\text { vision, headache. In toxicity, digital } \\
\text { is pro-arrhythmic, particularly in } \\
\text { concomitance with hypokalemia }\end{array}$ \\
\hline
\end{tabular}

Adapted from Kirchhof et al..$^{20}$.

In stable cases of subacute atrial fibrillation $(\geq 48 \mathrm{~h}$ ), there are three possibilities: (a) that a transesophageal echocardiogram is performed to detect left appendage thrombus and, only after that, electrical cardioversion is performed; (b) that the patient is anticoagulated for at least three weeks before electrical cardioversion, which will now be elective; (c) maintaining heart rate control with the same drugs as in Table $1^{24}$. If options (a) or (b) are chosen, a minimum of 4 weeks of full anticoagulation is required after cardioversion ${ }^{20}$ (Fig. 3). All patients undergoing electrical or chemical cardioversion require clinical observation and continuous cardiac monitoring for a period of not less than $2 \mathrm{~h}$. Ad eternum anticoagulation will depend on further evaluation.

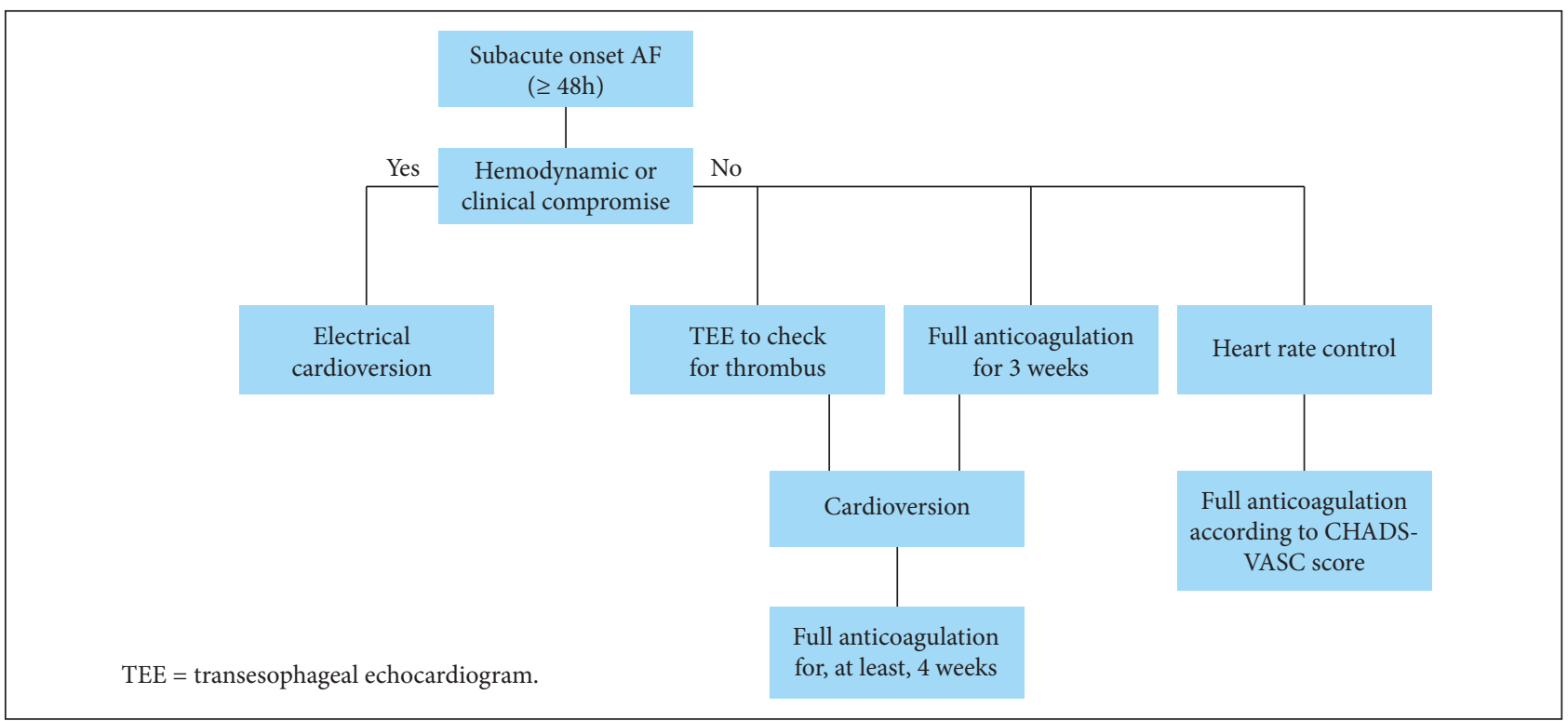

Figure 3. Urgent management of atrial fibrillation with sub-acute onset (> $48 \mathrm{~h}$ ).

\section{STRATEGIES FOR CARDIOVERSION AND RESTORATION OF SINUS RHYTHM}

Restoration to sinus rhythm can be achieved by electrical cardioversion or by pharmacological strategy, performed with antiarrhythmic drugs, namely, in Brazil, propafenone and amiodarone. Drugs available in other countries must be cited: flecainide, ibutilide and vernakalant. For decision making, factors such as availability, contraindications and adverse events must be considered ${ }^{25}$.

Flecainide, a class Ic antiarrhythmic agent, has an efficacy between $67-92 \%$ in $6 \mathrm{~h}$ for reversion of recent onset AF, mainly of short duration $(<24 \mathrm{~h})^{26}$. Propafenone, also in class Ic, although possibly less effective than 
flecainide for this purpose ${ }^{27}$, has its space due to the possibility of oral administration in the "pill-in-the-pocket" strategy, with good efficacy and tolerance, which consists of using a $600 \mathrm{mg}$ dose of propafenone in patients over $70 \mathrm{~kg}$ or $450 \mathrm{mg}$ in the others ${ }^{28,29}$. With a rate of adverse events between $7-16 \%$ of patients, the most common adverse event is presyncope, and the most feared is the evolution to atrial flutter with 1:1 conduction ${ }^{30}$. Although not recommended in official guidelines, it is a consensus among experts that the first use of this strategy is made in a hospital environment, under continuous monitoring. Class Ic antiarrhythmic drugs should be avoided in patients with structural, ischemic heart disease or left ventricular dysfunction ${ }^{25}$.

Ibutilide is a Vaughan-Williams class III antiarrhythmic with an efficacy of approximately $50 \%$ among several studies $^{31}$. It presents a notable risk of torsades de pointes due to the prolongation of the QT interval ${ }^{32}$.

The vernakalant acts on several ion channels, namely the $\mathrm{K}_{\text {ach }}$ current of the atria. Its efficacy in a randomized study is $51 \%$ of reversion to sinus rhythm ${ }^{33,34}$.

Amiodarone, rarely used in the acute phase in the countries of Europe and the United States, is a protagonist in Brazil. It has been used as an alternative to the aforementioned medications in cases of prolonged AF ( $>24-36 \mathrm{~h}$ ) or when there is a history of significant structural heart disease (with left ventricular ejection fraction $<40 \%)^{15}$.

Table 2 provides a brief summary of the drugs available for rhythm control in atrial fibrillation.

Table 2. Drugs available to control atrial fibrillation rhythm in Brazil.

\begin{tabular}{|c|c|c|c|c|}
\hline Drug & $\begin{array}{c}\text { Route of } \\
\text { administration }\end{array}$ & Loading dose & Maintenance dose & Adverse events \\
\hline Amiodarone & Intravenous & $\begin{array}{c}5-7 \mathrm{mg} / \mathrm{kg} \text { in } 1 \\
\text { to } 2 \mathrm{~h}\end{array}$ & $\begin{array}{l}50 \mathrm{mg} / \mathrm{h} \text { up to a } \\
\text { maximum of } 1 \mathrm{~g} \text { in } 24 \mathrm{~h}\end{array}$ & $\begin{array}{l}\text { Phlebitis, hypotension, bradycardia, } \\
\text { atrioventricular blocks. The reversal often } \\
\text { occurs late (after } 8 \text { to } 12 \text { h) }\end{array}$ \\
\hline Propafenone & Oral & $450-600$ mg & - & $\begin{array}{l}\text { Hypotension, atrial flutter with 1:1 conduction, } \\
\text { QRS prolongation. Avoid in patients with } \\
\text { ischemic or structural heart disease. }\end{array}$ \\
\hline
\end{tabular}

Adapted from Kirchhof et al. ${ }^{20}$.

Synchronized electrical cardioversion is a highly effective alternative to restore sinus rhythm, and treatment is recommended in cases where hemodynamic instability is presumably secondary to the high ventricular response of AF. Pretreatment with antiarrhythmic drugs can increase the rate of conversion to sinus rhythm and reduce the early recurrence of arrhythmia ${ }^{35,36}$. To maintain this effectiveness, it is prudent to start therapy one to three days before, in the case of propafenone; and three weeks earlier, in the case of amiodarone ${ }^{37}$.

The procedure involves the use of an electric shock synchronized to the QRS, in order to avoid the classic "R over T" phenomenon, which could trigger a polymorphic ventricular tachycardia with progression to cardiorespiratory arrest. The latest guidelines issued by the American and European Cardiology societies do not make any determination as to the exact shock load to be given ${ }^{7,20}$. In practice, an energy of 120 to $200 \mathrm{~J}$ is recommended for supraventricular arrhythmias of irregular rhythm, which is the case of atrial fibrillation ${ }^{38}$. Several other factors influence the quality of electrical cardioversion, including the use of the "biphasic" waveform ${ }^{39}$ and possibly the anteroposterior positioning of the defibrillation pads ${ }^{40}$.

A noteworthy observation is that the failure of electrical cardioversion must be distinguished between two situations: (a) transient return to sinus rhythm, with refractory atrial fibrillation afterwards; (b) complete absence of return to sinus rhythm. When the first scenario occurs, treatment with antiarrhythmic drugs can increase the likelihood of staying at a normal rhythm; in the second scenario, the strategies to be employed are: increasing the shock load, replacing a monophasic defibrillator for a biphasic model and changing the defibrillation vector ${ }^{36,41}$.

\section{RHYTHM OR HEART RATE LONG-TERM CONTROL}

For the long-term treatment of AF, there are two strategies: (a) heart rate control; (b) rhythm control, seeking to reverse sinus rhythm, either through the use of anti-arrhythmic drugs, or, in the modern era, with catheter ablation. 
The most classic study aimed at answering the question of which strategy is most beneficial to the patient was the AFFIRM trial, a randomized, multicenter, double-blind study that compared rhythm control with frequency control, which could be achieved with digoxin, beta-blockers or nondihydropyridine calcium channel blockers. The study, with the participation of four thousand patients, demonstrated, at the end of a five-year follow-up, that there is no superiority of the rhythm control strategy over frequency control, reaching a trend towards lower mortality in the group "rate control" $(\mathrm{p}=0.08)^{10}$. There are several criticisms regarding the study's methodology; for example, the fact that $52 \%$ of patients in the "frequency control" group were in sinus rhythm at the beginning of the study, something that is not the usual clinical practice ${ }^{42}$.

The RACE trial, although smaller (522 patients) ${ }^{43}$, was different from the AFFIRM in terms of selecting only patients with persistent atrial fibrillation refractory to attempts at cardioversion. The endpoint composed of death from cardiovascular causes, thromboembolic phenomena, bleeding, pacemaker implantation and adverse drug events was no different between the frequency and rhythm control groups. The study is criticized precisely for the selection of these outcomes, which are subjective and may have polluted the selection of the ideal sample.

It is recognized that one of the reasons why rhythm control was not superior in these studies is the safety profile of antiarrhythmic drugs used for rhythm control. Catheter ablation in cases of AF may allow selected patients to remain free from antiarrhythmic drugs. The CABANA trial randomized patients with symptomatic atrial fibrillation in a nonblinded intervention study comparing ablation strategies with frequency or rhythm control. By selecting 2204 patients, but with a 10.2\% loss of follow-up, CABANA demonstrated no differences between groups for the composite outcome of death, debilitating stroke, major bleeding or cardiorespiratory arrest $(\mathrm{p}=0.3)^{44}$. The greatest criticism of CABANA is due to the fact that it is not blind, the high rate of abandonment of the study and, mainly, the exaggerated crossover rate of the drug group to ablation $(27.5 \%)^{45}$.

\section{PREVENTION OF THROMBOEMBOLISM AND ANTICOAGULATION IN THE EMERGENCY}

One of the most important duties of the physician in caring for patients with AF in emergency departments is to prevent the occurrence of an embolic stroke. The development and embolization of atrial thrombi can occur in any form of AF (that is, paroxysmal, persistent or permanent). Although stroke is the most frequent clinical manifestation of embolization associated with AF, embolization to other sites in systemic and pulmonary circulations can also occur. Most embolic events occur shortly after successful cardioversion, which supports the view that the reversion of AF to sinus rhythm is responsible for thromboembolism, even after brief periods of $\mathrm{AF}^{46}$. The occurrence of a thromboembolic phenomenon is directly related to the duration of the arrhythmia: patients with AF lasting less than $48 \mathrm{~h}$ have a low risk of thromboembolic phenomena when reverting to sinus rhythm, whereas patients with uncertain duration of AF or lasting longer than $48 \mathrm{~h}$, the approach should be aimed at controlling the heart rate associated with antithrombotic therapy or, alternatively, cardioversion, after excluding the presence of intracavitary thrombus through transesophageal echocardiogram ${ }^{8,15,47}$.

As already mentioned, if an emergency cardioversion is chosen in a patient with unstable AF, a dose of 10,000 units of unfractionated heparin should be administered intravenously and in bolus. In situations of hemodynamic stability, in which an atrial fibrillation duration $\geq 48 \mathrm{~h}$ is estimated, the physician must decide between (a) performing a transesophageal echocardiogram to detect thrombi in the left atrial appendage and cardiovert up to $48 \mathrm{~h}$ after the examination, by anticoagulating by a minimum of 4 weeks after; (b) fully anticoagulated the patient for a minimum of 3 weeks and perform cardioversion electively, anticoagulating for a minimum of 4 weeks afterwards; (c) define the frequency control strategy. In all cases, the attending physician should define, based on the CHA(2) DS(2)-Vasc tool (or simply "CHADS-Vasc", Table 3) ${ }^{48}$, whether the patient will need ad eternum anticoagulation. Current guidelines recommend full anticoagulation in patients with AF (paroxysmal, permanent or persistent) with a CHADS-Vasc score $\geq 27,20$. More recent evidence suggests a statistical benefit in anticoagulating men with a score $\geq 1^{49}$. 
Table 3. Risk score for thromboembolic events in patients with atrial fibrillation.

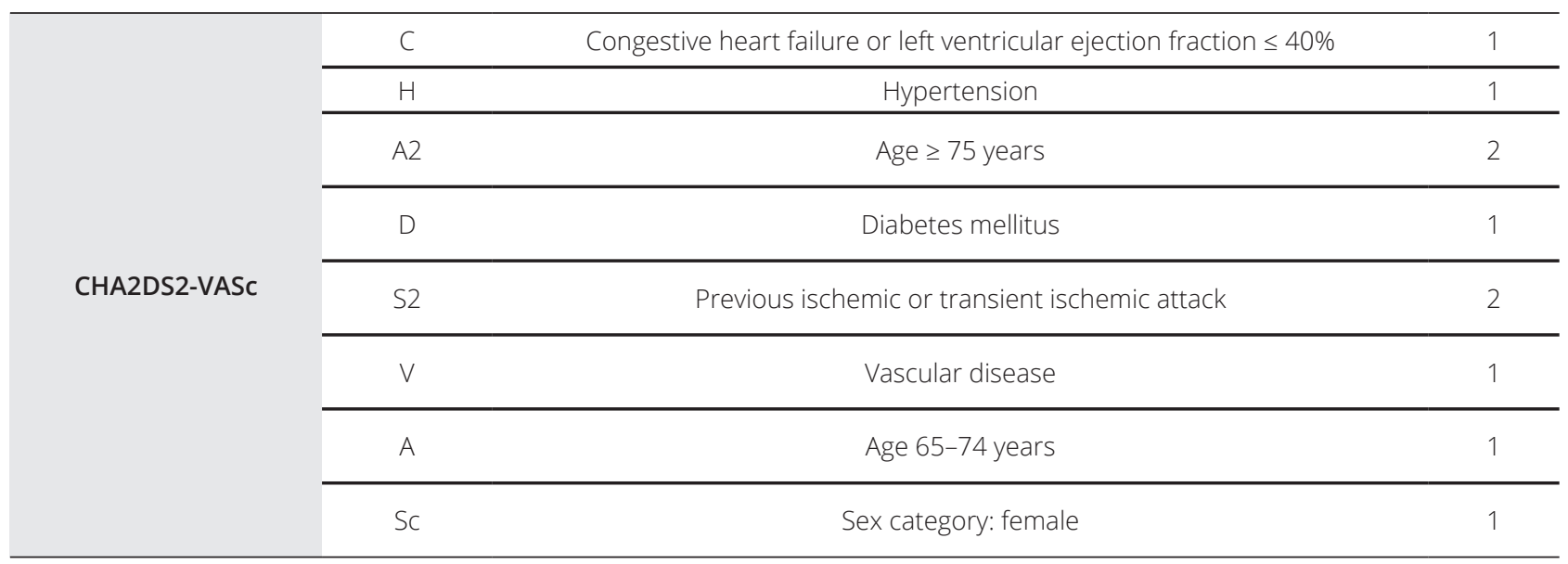

Direct oral anticoagulants (DOACs) have been shown to be safe and effective in preventing thromboembolism in patients with nonvalvular AF. Dabigatran is a direct inhibitor of thrombin. The clinical study that validated its use was RELY, which demonstrated the superiority of dabigatran at a dose of $300 \mathrm{mg}$ a day over dose-adjusted warfarin (INR between 2.0 and 3.0) in preventing thromboembolic events in patients with non-valvular $\mathrm{AF}^{50}$. In the specific scenario of cardioversion, a post-hoc analysis of RELY demonstrated that both doses (110 or $150 \mathrm{mg}$ bid) of dabigatran, used for at least 3 weeks, have a low risk of thromboembolism, comparable to the results with warfarin ${ }^{51}$. There are no studies of immediate cardioversion (in less than $24 \mathrm{~h}$ ) with Dabigatran.

Rivaroxaban is a direct factor Xa inhibitor used at doses of 15 or $20 \mathrm{mg}$ daily. The ROCKET-AF study included patients with nonvalvular AF and demonstrated noninferiority of rivaroxaban compared to warfarin in preventing thromboembolism in patients with non-valvular AF, with an adequate safety profile ${ }^{52}$. A post-hoc analysis of ROCKET-AF demonstrated statistical safety of cardioversion with restoration of sinus rhythm in patients with AF using rivaroxaban compared to warfarin. The anticoagulation time performed by the study has not been reported ${ }^{53}$. The $\mathrm{X}$-VeRT trial was the first randomized study to assess the efficacy and safety of DOACs compared to warfarin in the cardioversion setting, given at least $4 \mathrm{~h}$ before the procedure. There was no significant difference in the endpoints of embolic phenomena and bleeding ${ }^{54}$. A criticism of this study, as well as others on the same topic, is its limited statistical power: it would be necessary to randomize more than 40,000 patients to obtain a significant difference in embolic phenomena in X-VeRT ${ }^{55}$.

Apixaban is another factor Xa inhibitor, which has shown efficacy and safety in preventing embolic stroke compared to warfarin in patients with AF in the ARISTOTLE study, at doses of 5 or $2.5 \mathrm{mg}$ twice daily ${ }^{56}$. The posthoc analysis of this study demonstrated safety in the use of medication for the purpose of cardioversion. EMANATE, an open-label trial, evaluated the use of apixaban or usual therapy in patients not previously anticoagulated. It is a controversial study, due to the remarkable exclusion criteria, and for having performed transesophageal echocardiograms in several patients in the apixaban group. The results are positive for the reduction of embolic events in the group that used apixaban $(0 \% \times 0.83 \%){ }^{57}$.

Edoxaban was the last factor Xa inhibitor to reach the Brazilian market. The study that validated it was ENGAGE-AF, which used doses of 60 or $30 \mathrm{mg}$ daily compared to warfarin. Edoxaban proved to be non-inferior to warfarin in preventing embolic events and demonstrated significantly lower bleeding rates ${ }^{58}$. A post-hoc analysis of this study showed that there were no significant differences between using edoxaban or warfarin for cardioversion purposes $^{59}$. ENSURE-AF was a trial designed only to answer this question, for cardioversion in patients with more than $48 \mathrm{~h}$ of AF in two different groups: those who would undergo transesophageal echocardiography before cardioversion and those who would not. There was no significant difference in the rates of ischemic events and bleeding between groups ${ }^{60}$. 
Due to the heterogeneity among the populations of the studies, and the very low incidence of embolic events, cardioversion data in patients using DOACs are difficult to interpret and generalize. This issue is even more important when one considers the time the medication was used before cardioversion. Table 4 summarizes the studies and the minimum administration periods of times.

Table 4. Randomized studies that compared direct anticoagulants (DOACs) with the usual therapy for performing cardioversion. Adapted from ${ }^{55}$.

\begin{tabular}{|c|c|c|c|c|}
\hline Trial & Drugs & Minimum DOAC usage time & Ischemic events & Bleeding events \\
\hline$X-V e R T^{54}$ & Rivaroxaban $\times$ Warfarin & 1 to 5 days & $\begin{array}{c}\text { Rivaroxaban: 0,51\%. } \\
\text { Warfarin } 1.02 \% \\
\text { Cl: } 0.15-1.73\end{array}$ & $\begin{array}{c}\text { Rivaroxaban: } 0.61 \% \\
\text { Warfarin: } 0.8 \% \\
\text { Cl: } 0.21-2.67\end{array}$ \\
\hline EMANATE ${ }^{57}$ & $\begin{array}{c}\text { Apixaban x Warfarin } \\
+ \text { Heparin }\end{array}$ & $\begin{array}{c}2.5 \text { days or } 2 \text { h after a } 10 \text { or } 5 \mathrm{mg} \\
\text { loading dose }\end{array}$ & $\begin{array}{c}\text { Apixaban: } 0 \% \\
\text { Warfarin + heparin: } \\
0.83 \%(p=0.0164)\end{array}$ & $\begin{array}{c}\text { Apixaban: } 0.41 \% \\
\text { Warfarin + heparin: } \\
0,83 \%\end{array}$ \\
\hline ENSURE-AF ${ }^{60}$ & $\begin{array}{l}\text { Edoxaban x Warfarin } \\
+ \text { enoxaparin }\end{array}$ & $\begin{array}{l}\text { Those who did it in less than } 3 \\
\text { weeks followed the strategy of } \\
\text { performing a transesophageal } \\
\text { echocardiogram. Patients were } \\
\text { Cardioverted in average } 2 \text { days } \\
\text { after this exam. Minimum of } 2 \text { h. }\end{array}$ & $\begin{array}{c}\text { Edoxaban: }<1 \% . \\
\begin{array}{c}\text { Warfarin + enoxaparin: } \\
<1 \% \\
\text { Cl: } 0.06-5.88)\end{array}\end{array}$ & $\begin{array}{c}\text { Edoxaban: < 1\%. } \\
\text { Warfarin }+ \\
\text { enoxaparin: < 1\%. } \\
\text { Cl: } 0.64-3.55)\end{array}$ \\
\hline
\end{tabular}

\section{CONCLUSION}

Atrial fibrillation is a common situation in emergency rooms with high morbidity. There are several viable strategies to be employed, which can result in hospital discharge safely for a given patient population, minimizing costs to the health system. The decision about controlling the rhythm or heart rate must be individualized and based on the duration of the arrhythmia, thromboembolic risk, symptoms and signs of hemodynamic instability. Prevention of thromboembolism is the main objective in the care of AF and doctors working in emergency units must be familiar with the current care protocols.

\section{REFERENCES}

1. Chugh SS, Havmoeller R, Narayanan K, Singh D, Rienstra M, Benjamin EJ, et al. Worldwide epidemiology of atrial fibrillation: a global burden of disease 2010 study. Circulation. 2014;129(8):837-47. https://doi.org/10.1161/CIRCULATIONAHA.113.005119

2. McDonald AJ, Pelletier AJ, Ellinor PT, Camargo Junior CA. Increasing US emergency department visit rates and subsequent hospital admissions for atrial fibrillation from 1993 to 2004. Ann Emerg Med. 2008;51(1):58-65. https://doi.org/10.1016/j. annemergmed.2007.03.007

3. Stiell IG, Macle L. Canadian Cardiovascular Society Atrial Fibrillation Guidelines 2010: Management of recent-onset atrial fibrillation and flutter in the emergency department. Can J Cardiol. 2011;27(1):38-46. https://doi.org/10.1016/j.cjca.2010.11.014

4. Conen D. Epidemiology of atrial fibrillation. Eur Heart J. 2018;39(16):1323-4. https://doi.org/10.1093/eurheartj/ehy171

5. Staerk L, Sherer JA, Ko D, Benjamin EJ, Helm RH. Atrial fibrillation: epidemiology, pathophysiology, and clinical outcomes. Circ Res. 2017;120(9):1501-17. https://doi.org/10.1161/CIRCRESAHA.117.309732

6. Middeldorp ME, Pathak RK, Meredith M, Mehta AB, Elliott AD, Mahajan R, et al. PREVEntion and regReSsive Effect of weight-loss and risk factor modification on Atrial Fibrillation: the REVERSE-AF study. Europace. 2018;20(12):1929-35. https://doi.org/10.1093/ europace/euy117 
7. January CT, Wann LS, Alpert JS, Calkins H, Cigarroa JE, Cleveland Junior JC, et al. 2014 AHA/ACC/HRS Guideline for the Management of Patients with Atrial Fibrillation: Executive Summary: A Report of the American College of Cardiology/American Heart Association Task Force on Practice Guidelines and the Heart Rhythm Society. Circulation. 2014;130(23):2071-104. https://doi.org/10.1161/ CIR.0000000000000040

8. January CT, Wann LS, Calkins H, Chen LY, Cigarroa JE, Cleveland Junior JC, et al. 2019 AHA/ACC/HRS Focused Update of the 2014 AHA/ACC/HRS Guideline for the Management of Patients With Atrial Fibrillation: A report of the American College of Cardiology/ American Heart Association Task Force on Clinical Practice Guidelines and the Heart Rhythm Society. Heart Rhythm. 2019;16(8):e6693. https://doi.org/10.1016/j.hrthm.2019.01.024

9. Calkins H, Hindricks G, Cappato R, Kim Y-H, Saad EB, Aguinaga L, et al. 2017 HRS/EHRA/ECAS/APHRS/SOLAECE Expert consensus statement on catheter and surgical ablation of atrial fibrillation. Europace. 2018;20(1):e1-60. https://doi.org/10.1093/europace/ eux274

10. The Atrial Fibrillation Follow-up Investigation of Rhythm Management (AFFIRM) Investigators. A comparison of rate control and rhythm control in patients with atrial fibrillation. N Engl J Med. 2002;347(23):1825-33. https://doi.org/10.1056/NEJMoa021328

11. Kelly JP, DeVore AD, Wu J, Hammill BG, Sharma A, Cooper LB, et al. Rhythm control versus rate control in patients with atrial fibrillation and heart failure with preserved ejection fraction: insights from get with the Guidelines-Heart Failure. J Am Heart Assoc. 2019;8(24):e011560. https://doi.org/10.1161/JAHA.118.011560

12. Marrouche NF, Brachmann J, Andresen D, Siebels J, Boersma L, Jordaens L, et al. Catheter ablation for atrial fibrillation with heart failure. N Engl J Med. 2018;378(5):417-27. https://doi.org/10.1056/NEJMoa1707855

13. Russo V, Navarin S, Zampini G, Magrini L, Mann C, Muiesan ML, et al. Management of atrial fibrillation in the emergency department: current approach and future expectations. Eur Rev Med Pharmacol Sci. 2013;17(23):3132-47.

14. Scheuermeyer FX, Pourvali R, Rowe BH, Grafstein E, Heslop C, MacPhee J, et al. Emergency department patients with atrial fibrillation or flutter and an acute underlying medical illness may not benefit from attempts to control rate or rhythm. Ann Emerg Med. 2015;65(5):511-22. https://doi.org/10.1016/j.annemergmed.2014.09.012

15. Dietrich CO, Cirenza C, Costa GDF, Paola AAV. Approach of atrial fibrillation in the emergency department: rate or rhythm control? J Cardiac Arrythmias. 2013;26(2):107-15.

16. Coll-Vinent B, Sala X, Fernández C, Bragulat E, Espinosa G, Miró O, et al. Sedation for cardioversion in the emergency department: Analysis of effectiveness in four protocols. Ann Emerg Med. 2003;42(6):767-72. https://doi.org/10.1016/S0196-0644(03)00510-9

17. Soeiro AM, Leal TCAT, Soeiro MCFA, Serrano Junior CV, Oliveira Junior MT. Atrial fibrillation with high ventricular rate in emergency room: What's the best strategy for treatment? Rev Assoc Med Bras. 2016;62(9):879-85. https://doi.org/10.1590/1806-9282.62.09.879

18. Khan IA. Atrial stunning: Determinants and cellular mechanisms. Am Heart J. 2003;145(5):787-94. https://doi.org/10.1016/S00028703(03)00086-3

19. Crijns HJGM, Weijs B, Fairley A-M, Lewalter T, Maggioni AP, Martín A, et al. Contemporary real life cardioversion of atrial fibrillation: Results from the multinational RHYTHM-AF study. Int J Cardiol. 2014;172(3):588-94. https://doi.org/10.1016/j.ijcard.2014.01.099

20. Kirchhof P, Benussi S, Kotecha D, Ahlsson A, Atar D, Casadei B, et al. 2016 ESC Guidelines for the Management of Atrial Fibrillation developed in collaboration with EACTS. Eur Heart J. 2016;37(38):2893-962. https://doi.org/10.1093/eurheartj/ehw210

21. Danias PG, Caulfield TA, Weigner MJ, Silverman DI, Manning WJ. Likelihood of spontaneous conversion of atrial fibrillation to sinus rhythm. J Am Coll Cardiol. 1998;31(3):588-92. https://doi.org/10.1016/S0735-1097(97)00534-2

22. Garg A, Khunger M, Seicean S, Chung MK, Tchou PJ. Incidence of thromboembolic complications within 30 days of electrical cardioversion performed within 48 hours of atrial fibrillation onset. JACC Clin Electrophysiol. 2016;2(4):487-94. https://doi. org/10.1016/j.jacep.2016.01.018

23. Pluymaekers NAHA, Dudink EAMP, Luermans JGLM, Meeder JG, Lenderink T, Widdershoven J, et al. Early or delayed cardioversion in recent-onset atrial fibrillation. N Engl J Med. 2019;380(16):1499-508. https://doi.org/10.1056/NEJMoa1900353

24. Long B, Robertson J, Koyfman A, Maliel K, Warix JR. Emergency medicine considerations in atrial fibrillation. Am J Emerg Med. 2018;36(6):1070-8. https://doi.org/10.1016/j.ajem.2018.01.066

25. Piccini JP, Fauchier L. Rhythm control in atrial fibrillation. Lancet. 2016;388(10046):829-40. https://doi.org/10.1016/S01406736(16)31277-6

26. Khan IA. Oral loading single dose flecainide for pharmacological cardioversion of recent-onset atrial fibrillation. Int J Cardiol. 2003;87(2-3):121-8. https://doi.org/10.1016/S0167-5273(02)00467-9 
27. Martínez-Marcos FJ, García-Garmendia JL, Ortega-Carpio A, Fernández-GómezJM, SantosJM, Camacho C. Comparison of intravenous flecainide, propafenone, and amiodarone for conversion of acute atrial fibrillation to sinus rhythm. Am J Cardiol. 2000;86(9):950-3. https://doi.org/10.1016/S0002-9149(00)01128-0

28. Alboni P, Botto GL, Baldi N, Luzi M, Russo V, Gianfranchi L, et al. Outpatient treatment of recent-onset atrial fibrillation with the "pillin-the-pocket" approach. N Engl J Med. 2004;351(23):2384-91. https://doi.org/10.1056/NEJMoa041233

29. Boriani G, Biffi M, Capucci A, Botto GL, Broffoni T, Rubino I, et al. Oral propafenone to convert recent-onset atrial fibrillation in patients with and without underlying heart disease: a randomized, controlled trial. Ann Intern Med. 1997;126(8):621-5. https://doi. org/10.7326/0003-4819-126-8-199704150-00006

30. Andrade JG, MacGillivray J, Macle L, Yao RJR, Bennett M, Fordyce CB, et al. Clinical effectiveness of a systematic "pill-in-thepocket" approach for the management of paroxysmal atrial fibrillation. Heart Rhythm. 2018;15(1):9-16. https://doi.org/10.1016/j. hrthm.2017.10.002

31. Reisinger J, Gatterer E, Lang W, Vanicek T, Eisserer G, Bachleitner T, et al. Flecainide versus ibutilide for immediate cardioversion of atrial fibrillation of recent onset. Eur Heart J. 2004;25(15):1318-24. https://doi.org/10.1016/j.ehj.2004.04.030

32. Stambler BS, Wood MA, Ellenbogen KA, Perry KT, Wakefield LK, VanderLugt JT. Efficacy and safety of repeated intravenous doses of ibutilide for rapid conversion of atrial flutter or fibrillation. Circulation. 1996;94(7):1613-21. https://doi.org/10.1161/01.CIR.94.7.1613

33. Roy D, Pratt CM, Torp-Pedersen C, Wyse DG, Toft E, Juul-Moller S, et al. Vernakalant hydrochloride for rapid conversion of atrial fibrillation: a phase 3, randomized, placebo-controlled trial. Circulation. 2008;117(12):1518-25. https://doi.org/10.1161/ CIRCULATIONAHA.107.723866

34. Bash LD, Buono JL, Davies GM, Martin A, Fahrbach K, Phatak H, et al. Systematic review and meta-analysis of the efficacy of cardioversion by vernakalant and comparators in patients with atrial fibrillation. Cardiovasc Drugs Ther. 2012;26(2):167-79. https:// doi.org/10.1007/s10557-012-6374-4

35. Singh SN, Tang XC, Reda D, Singh BN. Systematic electrocardioversion for atrial fibrillation and role of antiarrhythmic drugs: A substudy of the SAFE-T trial. Heart Rhythm. 2009;6(2):152-5. https://doi.org/10.1016/j.hrthm.2008.10.036

36. Bianconi L, Mennuni M, LukicV, Castro A, Chieffi M, Santini M. Effects of oral propafenone administration before electrical cardioversion of chronic atrial fibrillation: A placebo-controlled study. J Am Coll Cardiol. 1996;28(3):700-6. https://doi.org/10.1016/07351097(96)00230-6

37. Singh $B N$, Singh $S N$, Reda DJ, Tang XC, Lopez $B$, Harris CL, et al. Amiodarone versus sotalol for atrial fibrillation. $N$ Engl J Med. 2005;352(18):1861-72. https://doi.org/10.1056/NEJMoa041705

38. Link MS, Atkins DL, Passman RS, Halperin HR, Samson RA, White RD, et al. Part 6: Electrical therapies: automated external defibrillators, defibrillation, cardioversion, and pacing. Circulation. 2010;122(18 Suppl 3):S706-19. https://doi.org/10.1161/ CIRCULATIONAHA.110.970954

39. Mittal S, Ayati S, Stein KM, Schwartzman D, Cavlovich D, Tchou PJ, et al. Transthoracic cardioversion of atrial fibrillation: comparison of rectilinear biphasic versus damped sine wave monophasic shocks. Circulation. 2000;101(11):1282-7. https://doi.org/10.1161/01. CIR.101.11.1282

40. DeSilva RA, Graboys TB, Podrid PJ, Lown B. Cardioversion and defibrillation. Am Heart J. 1980;100(6 Pt 1):881-95. https://doi. org/10.1016/0002-8703(80)90071-X

41. Gurevitz OT, Ammash NM, Malouf JF, Chandrasekaran K, Rosales AG, Ballman KV, et al. Comparative efficacy of monophasic and biphasic waveforms for transthoracic cardioversion of atrial fibrillation and atrial flutter. Am Heart J. 2005;149(2):316-21. https:// doi.org/10.1016/j.ahj.2004.07.007

42. Falk RH. Rate control is preferable to rhythm control in the majority of patients with atrial fibrillation. Circulation. 2005;111(23):314150. https://doi.org/10.1161/CIRCULATIONAHA.104.485565

43. Van Gelder IC, Hagens VE, Bosker HA, Kingma JH, Kamp O, Kingma T, et al. A comparison of rate control and rhythm control in patients with recurrent persistent atrial fibrillation. N Engl J Med. 2002;347(23):1834-40. https://doi.org/10.1056/NEJMoa021375

44. Packer DL, Mark DB, Robb RA, Monahan KH, Bahnson TD, Poole JE, et al. Effect of catheter ablation vs antiarrhythmic drug therapy on mortality, stroke, bleeding, and cardiac arrest among patients with atrial fibrillation: The CABANA randomized clinical trial. JAMA. 2019;321(13):1261-74. https://doi.org/10.1001/jama.2019.0693

45. Vasconcelos JTM. Reflections on CABANA Trial (Catheter Ablation versus Antiarrhythmic Drug Therapy for Atrial Fibrillation Trial). J Cardiac Arrythmias. 2019;32(2):73-5. https://doi.org/10.24207/jca.v32i2.989_PT 
46. Berger M, Schweitzer P. Timing of thromboembolic events after electical cardioversion of atrial fibrillation or flutter: a retrospective analysis. Am J Cardiol. 1998;82(12):1545-7. https://doi.org/10.1016/S0002-9149(98)00704-8

47. Wakai A, O'Neill J. Emergency management of atrial fibrillation. Postgrad Med J. 2003;79(932):313-9. https://doi.org/10.1136/ pmj.79.932.313

48. Olesen JB, Lip GYH, Hansen ML, Hansen PR, Tolstrup JS, Lindhardsen J, et al. Validation of risk stratification schemes for predicting stroke and thromboembolism in patients with atrial fibrillation: nationwide cohort study. BMJ. 2011;342:d124. https://doi. org/10.1136/bmj.d124

49. Lip GYH, Nielsen PB. Should patients with atrial fibrillation and 1 stroke risk factor (CHA2DS2-VASc score 1 in men, 2 in women) be anticoagulated? Yes: Even 1 stroke risk factor confers a real risk of stroke. Circulation. 2016;133(15):1498-503. https://doi. org/10.1161/CIRCULATIONAHA.115.016713

50. Connolly SJ, Ezekowitz MD, Yusuf S, Eikelboom J, Oldgren J, Parekh A, et al. Dabigatran versus warfarin in patients with atrial fibrillation. N Engl J Med. 2009;361(12):1139-51. https://doi.org/10.1056/NEJMoa0905561

51. Nagarakanti R, Ezekowitz MD, Oldgren J, Yang S, Chernick M, Aikens TH, et al. Dabigatran versus warfarin in patients with atrial fibrillation: an analysis of patients undergoing cardioversion. Circulation. 2011;123(2):131-6. https://doi.org/10.1161/ CIRCULATIONAHA. 110.977546

52. Patel MR, Mahaffey KW, Garg J, Pan G, Singer DE, Hacke W, et al. Rivaroxaban versus warfarin in nonvalvular atrial fibrillation. N Engl J Med. 2011;365(10):883-91. https://doi.org/10.1056/NEJMoa1009638

53. Piccini JP, Stevens SR, Lokhnygina Y, Patel MR, Halperin JL, Singer DE, et al. Outcomes after cardioversion and atrial fibrillation ablation in patients treated with rivaroxaban and warfarin in the ROCKET AF Trial. J Am Coll Cardiol. 2013;61(19):1998-2006. https:// doi.org/10.1016/j.jacc.2013.02.025

54. Cappato R, Ezekowitz MD, Klein AL, Camm AJ, Ma C-S, Heuzey J-YL, et al. Rivaroxaban vs. vitamin K antagonists for cardioversion in atrial fibrillation. Eur Heart J. 2014;35(47):3346-55. https://doi.org/10.1093/eurheartj/ehu367

55. Warden BA, Mackay J, Jafari M, Willman A, Stecker EC. Use of direct oral anticoagulants among patients undergoing cardioversion: the importance of timing before cardioversion. J Am Heart Assoc. 2018;7(22):e010854. https://doi.org/10.1161/JAHA.118.010854

56. Granger CB, Alexander JH, McMurray JJV, Lopes RD, Hylek EM, Hanna M, et al. Apixaban versus warfarin in patients with atrial fibrillation. N Engl J Med. 2011;365(11):981-92. https://doi.org/10.1056/NEJMoa1107039

57. Ezekowitz MD, Pollack Junior CV, Halperin JL, England RD, Nguyen SV, Spahr J, et al. Apixaban compared to heparin/vitamin K antagonist in patients with atrial fibrillation scheduled for cardioversion: The EMANATE Trial. Eur Heart J. 2018;39(32):2959-71. https://doi.org/10.1093/eurheartj/ehy148

58. Giugliano RP, Ruff CT, Braunwald E, Murphy SA, Wiviott SD, Halperin JL, et al. Edoxaban versus warfarin in patients with atrial fibrillation. N Engl J Med. 201328;369(22):2093-104. https://doi.org/10.1056/NEJMoa1310907

59. Plitt A, Ezekowitz MD, Caterina R, Nordio F, Peterson N, Giugliano RP, et al. Cardioversion of atrial fibrillation in ENGAGE AFUTIMI 48. Clin Cardiol. 2016;39(6):345-6. https://doi.org/10.1002/clc.22537

60. Goette A, Merino JL, Ezekowitz MD, Zamoryakhin D, Melino M, Jin J, et al. Edoxaban versus enoxaparin-warfarin in patients undergoing cardioversion of atrial fibrillation (ENSURE-AF): a randomised, open-label, phase 3b trial. Lancet. 2016;388(10055):1995-2003. https://doi.org/10.1016/S0140-6736(16)31474-X 